\title{
COOPERAR PARA COMPETIR: LA COOPERACIÓN ENTRE EMPRESAS COMO ESTRATEGIA PARA EL FOMENTO DE LA COMPETITIVIDAD
}

\section{COOPERATE TO COMPETE: COOPERATION AMONG FIRMS AS A STRATEGY TO ENCOURAGE THE COMPETITIVENESS}

\author{
FRANCISCO LLAMAZARES REDONDO \\ Profesor y Director del Departamento de Informática \\ Esic Marketing School \\ francisco.llamazares@esic.es \\ SERGIO A. BERUMEN \\ Profesor titular de Economía Aplicada \\ Universidad Rey Juan Carlos \\ sergio.berumen@urjc.es \\ Fecha recepción: 20 de octubre de 2010 \\ Fecha aceptación: 3 de mayo de 2011 \\ doi: 10.5209/rev_PADE.2011.v22.4
}

\section{RESUMEN}

La conformación de clusters representa gráficamente el flujo de productos y servicios en un sector industrial. Éstos se integran tanto por los proveedores de materia prima como por los encargados de la distribución final de productos y los servicios post-venta. La conformación de clusters permite a los agentes participantes una serie de ventajas que de forma aislada difícilmente se podrían alcanzar; estas ventajas son un aliciente adicional que tienen los agentes para cooperar, aunque en particular se destaca la optimización de la competitividad. Mediante la conformación de organizaciones cooperativas y clusters a los agentes les es posible lograr una mayor flexibilidad y la eventualidad para obtener nuevos conocimientos respecto a las actividades que conforman la cadena de valor.

PALABRAS CLAVE: cooperación entre empresas, competitividad y clusters.

JEL: L23, L26, L29.

\section{INTRODUCCIÓN}

Para el enfoque neoschumpeteriano la elección de las estrategias de las empresas está circunscrita en: i) los recursos con los que cuentan y por la identificación que los directivos tengan con los proyectos; y ii), por las características de los sistemas de financiación, de innovación y de producción que, junto con el tipo de sector empresarial y fuente y uso de tecnología, determinan el entorno empresarial en el 
Llamazares, Francisco y Berumen, Sergio A. Cooperar para competir: la cooperación entre empresas como estrategia para el fomento de la competitividad.

que se desenvuelven las empresas. En el cuadro 1 se muestran los diferentes tipos de estrategia que están a disposición de las empresas.

Cuadro 1. Tipos de estrategias (corporativa, tecnológica y de productos).

\begin{tabular}{|l|c|c|c|}
\hline $\begin{array}{l}\text { Sectores económicos por tipo } \\
\text { de rivalidad empresarial } \\
\text { dominante, y por fuente y uso } \\
\text { de tecnología }\end{array}$ & $\begin{array}{c}\text { Estrategias } \\
\text { Corporativas }\end{array}$ & $\begin{array}{c}\text { Estrategias } \\
\text { Tecnológicas }\end{array}$ & $\begin{array}{c}\text { Estrategias por } \\
\text { Productos }\end{array}$ \\
\hline $\begin{array}{l}\text { Industrias intensivas en recursos } \\
\text { naturales }\end{array}$ & Líder & Ofensiva & Genérica \\
\hline $\begin{array}{l}\text { Industrias dominadas por el } \\
\text { proveedor }\end{array}$ & Seguidor cercano & Defensiva & $\begin{array}{c}\text { Ampliamente } \\
\text { diversificada }\end{array}$ \\
\hline $\begin{array}{l}\text { Industrias intensivas en } \\
\text { información }\end{array}$ & Seguidor lejano & Imitativa & $\begin{array}{c}\text { Diversificación } \\
\text { limitada }\end{array}$ \\
\hline Industrias intensivas en escala & Inmóvil & Dependiente & Nicho \\
\hline Industrias intensivas en escala & Salida & Tradicional & \\
\hline $\begin{array}{l}\text { Industrias de proveedores } \\
\text { especializados }\end{array}$ & & Oportunista & \\
\hline \multicolumn{2}{|l|}{ Fuente: elaboración propia a partir de Freeman, Soete (1997) y Lazonick y West (1998). } \\
\hline
\end{tabular}

En este artículo se verá que la conformación de clusters permite a los agentes participantes una serie de ventajas que de forma aislada difícilmente se podrían alcanzar; estas ventajas son un aliciente adicional que tienen los agentes para cooperar, aunque en particular se destaca la optimización de la competitividad. Por medio de la cooperación a los agentes les es posible lograr una mayor flexibilidad y el acceso a nuevos conocimientos e información respecto a las actividades que conforman la cadena de valor. La principal contribución de este trabajo se centra en exponer: i) las razones estratégicas y las razones operativas para la conformación de empresas cooperantes; ii) las condiciones ambientales para la conformación de empresas cooperantes; iii) las características de los clusters; y iv), mostrar la clasificación tecnológica de las empresas en base a sus actividades económicas.

\section{LAS EMPRESAS Y LOS CLUSTERS}

La diferencia entre la empresa y el cluster radica en el grado de soberanía que existe entre una y otro. La organización se caracteriza porque la soberanía que detenta es plena y su interés es la autorregulación conforme a los principios que ésta determina. Mientras que el cluster tiene el interés de agrupar a diversas organizaciones que acceden a cooperar en la concreción de fines comunes entre ellas. Cada una de estas organizaciones cederá una parte de su soberanía y conformarán un cluster estratégico, pues comprende que el todo siempre será mucho más que la suma de las partes en lo individual.

De acuerdo con Karlsson (2007), en las organizaciones y en los clusters actuales existen patrones de conductas regulares y predecibles, muchas veces formalizadas por medio de los manuales y protocolos de funciones y procedimientos. En éstos, los individuos tratan de reproducir esos patrones de conducta a través de la asimilación de información, por imitación o aprendizaje. Sin embargo, durante este proceso es 
Llamazares, Francisco y Berumen, Sergio A. Cooperar para competir: la cooperación entre empresas como estrategia para el fomento de la competitividad.

posible que debido a una acumulación de información, o por la presencia de errores en el proceso de transmisión de la información, pueden surgir procesos diferentes, que de impactar negativamente en la organización pueden propiciar su desaparición, pero si es una interacción positiva, entonces esos nuevos procesos perdurarán y transmitirán las características adquiridas mediante el aprendizaje. Esto se sustenta en los principios del modelo de evolución Lamarckiana, en el cual, los individuos, al interactuar entre sí en las organizaciones, asumen roles y crean cultura (a diferencia de las células, las plantas o los animales, los seres humanos poseen la capacidad de desear una conducta o un proceder en el futuro), por lo que al nivel de la organización se establecen procesos de planificación que generan una inducción a los cambios. En función de lo anterior, es posible deducir que los procesos de innovación pueden ser el resultado de cambios inducidos y planificados, o de cambios revolucionarios surgidos por procesos aleatorios y derivados de las interacciones con las variables medioambientales, tecnológicas y económicas.

Las grandes transiciones que se observan a nivel macro que están asociadas con el surgimiento de nuevas formas organizacionales: hay simetría cuando se tiene una hoja en blanco, pero no hay información; pero cuando la simetría se rompe, es decir, cuando se escribe en esa hoja en blanco, entonces se establece un incremento de la organización y de la información. De igual manera, las organizaciones y los clusters surgen debido a un proceso de autoorganización de los agentes que las conforman en la búsqueda de un fin determinado, y se desarrollan a partir de las interacciones tanto internas como externas, y es cuando evolucionan de manera gradual hasta que (a través de un proceso de innovación) se generan revoluciones debido a un acontecimiento espontáneo. Este acontecimiento genera un impacto como consecuencia de los artefactos culturales y tecnológicos (que generan los mismos individuos, las organizaciones y los clusters con los que co-evolucionan), y a partir de ahí surge un proceso de evolución con el mejoramiento de las tecnologías y los procesos que paulatinamente darán lugar a nuevas estructuras organizacionales y clusters estratégicos que sean capaces de adaptarse al ambiente que prevalece.

En virtud de lo anterior, las organizaciones y los clusters modifican sus procesos y estructuras en función de la evolución biológica, económica, sociocultural y tecnológica, de tal forma que los artefactos culturales y tecnológicos que fueron creados y modificados, a su vez nos modifican a nosotros, a las organizaciones y a los clusters. Como lo señalan Ayele et.al (2010), es habitual que en el universo tecnológico y cultural se presenten hechos innovadores de gran trascendencia que constituyen revoluciones, y que ayudan a alcanzar metas humanas y a alcanzar un nuevo nivel de orden, como ocurrió con las así llamadas revoluciones agrícolas, industrial y del conocimiento.

Generalmente los grupos tienden a formar sistemas y no a funcionar de manera aislada: están vinculados con otros grupos y sistemas, evolucionan en conjunto y utilizan los instrumentos o máquinas que la humanidad ha inventado. En este nivel se encuentran a las poblaciones de organismos y a las comunidades determinadas por la cultura y los desarrollos tecnológicos. Y es precisamente esa interacción entre los sistemas o grupos de esos subsistemas, junto con los instrumentos culturales o tecnológicos que ellos crean, lo que ha propiciado las denominadas grandes olas o transiciones, que de acuerdo con Kondratiev (1926 y 1928) cada ola termina cuando 
Llamazares, Francisco y Berumen, Sergio A. Cooperar para competir: la cooperación entre empresas como estrategia para el fomento de la competitividad.

las tecnologías llegan a su límite y eventualmente se manifiesta en una caída del crecimiento económico.

Otra forma de analizar la evolución en las organizaciones y los clusters es a partir de la metáfora de la complejidad y el caos, desarrollada por autores como Burrell y Morgan (1979) y más tarde por Garud y Kumaraswamy (1993). La analogía entre los sistemas biológicos y los sociales ha sido retomada por diferentes autores de diversas disciplinas. Bajo este enfoque la selección natural no es solamente un proceso biológico, sino además es un proceso termodinámico, como lo señala la teoría del caos. La selección natural es una transición del caos al orden mediante pasos lentos y aleatorios de mutación, selección y supervivencia del más apto. En situaciones lejanas al equilibrio se pueden amplificar las fluctuaciones de las variables del sistema y llevar a inestabilidades, a partir de las cuales aparecen organizaciones y estructuras nuevas (o evoluciones cualitativas de las existentes, como los clusters). Incluso en sistemas de cambio lento pueden aparecer saltos y discontinuidades, seguidos de una reorganización estructural del sistema. En determinados puntos críticos o bifurcaciones, eventos muy pequeños pueden tener efectos macro significativos, en el sentido de que ellos deciden qué camino va a tomar el sistema, hecho que introduce un elemento aleatorio y hace indeterminados a los procesos auto-organizativos en condiciones de ausencia de equilibrio.

En estos procesos se combinan la necesidad y el azar, lo que genera trayectorias históricas únicas e irreversibles y en las cuales el futuro, en lugar de estar dado, se crea a lo largo de un sendero evolutivo. De igual forma, muchos de estos sistemas llevan a la emergencia espontánea de estructuras macroscópicas coherentes a partir del comportamiento aparentemente in-coordinado de sus partes componentes a nivel micro. Incluso en algunas circunstancias el equilibrio es sinónimo de desorden y caos, mientras que del no equilibrio surge, a través de procesos autoorganizativos, el orden. Para Prigogine (1997, pp. 150 y sig.) la vinculación entre estas ideas con las ciencias sociales es evidente, porque para él la sociedad es un sistema no lineal, donde lo que hace cada individuo repercute y se amplifica por efecto de sus múltiples vínculos con el medio social.

Esta no linealidad ha crecido notoriamente como resultado de la intensificación de intercambios de todo tipo, propios de las sociedades postmodernas. En los análisis de los economistas de pensamiento neoschumpeteriano se enfatiza la necesidad del análisis micro, ya que cualquier programa de investigación debe reposar en alguna teoría sobre el comportamiento de los individuos y sus interacciones (sobre este particular, véase Verspagen (2002) y Foster (2004)). Tales micro-fundamentos deben basarse en la consideración explícita de procesos evolucionistas de aprendizaje y selección entre agentes heterogéneos y limitadamente racionales que operan en ambientes no estacionarios y complejos. Estos nuevos microfundamentos parten de los siguientes hechos:

- Las creencias y convenciones individuales y colectivas son relevantes.

- En un contexto de información imperfecta es preciso que existan instituciones que generen un esquema de incentivos, evaluación de desempeños y flujos de información.

- Los comportamientos institucionalizados (gobernados por reglas que se aplican repetidamente a lo largo del tiempo) pueden tener un efecto estabilizador sobre las variables macro. 
Llamazares, Francisco y Berumen, Sergio A. Cooperar para competir: la cooperación entre empresas como estrategia para el fomento de la competitividad.

- Los intercambios económicos son imposibles sin normas preexistentes y organizaciones de monitoreo.

- Las conductas de los individuos deben ser descritas a partir de rutinas no óptimas que cambian sólo lentamente a lo largo del tiempo; estas rutinas operan en el mismo sentido que las instituciones, al contabilizar los comportamientos heterogéneos de los individuos.

- Como en su día lo estudiaron Nelson y Winter (1982), Winter (1987) y Teece (1998), todos ellos notables autores del pensamiento neoschumpeteriano, las rutinas son el resultado de procesos de aprendizaje en los que se consolidan formas de respuesta casi automáticas y que incluyen grandes cantidades de conocimiento tácito; al mismo tiempo, los individuos, al actuar en ambientes complejos y no estacionarios, deben realizar desarrollos creativos en base a sus propias rutinas.

Por consiguiente, Collison (2001) señala que tanto el comportamiento individual como el colectivo se describen en términos de reglas de decisión rutinizadas, criterios de mayor nivel que gobiernan su implantación y, finalmente, procesos de aprendizaje que cambian las reglas (generalmente escritas) y las meta-reglas (generalmente tácitas, como las convenciones). Pero no sólo los procesos de aprendizaje son importantes, sino también los de olvido, ya que los hábitos adquiridos pueden bloquear la incorporación de nuevos conocimientos (véase, Pentland, Haerem y Hillison (2010)). Parte de este proceso de olvido no sólo se relaciona con la eliminación de conocimientos, sino también de conocimientos, habilidades, aptitudes y valores. El carácter interactivo, social y culturalmente enraizado de los procesos de aprendizaje, generalmente implican secuencias de intercambios de mensajes entre personas de diferentes departamentos, niveles, empresas o incluso entre personas provenientes de diversos ámbitos de la sociedad. El aprendizaje también se enmarca en una determinada infraestructura institucional (sistema educativo, comunicaciones, etc.) y en esquemas específicos de apropiabilidad de sus retornos (patentes, derechos de propiedad industrial e intelectual, marcas registradas, etc.). Puede ocurrir, entonces, que instituciones que en ciertos períodos han sido proclives a estimular la innovación, pueden dejar de hacerlo si las circunstancias cambian.

\section{RAZONES ESTRATÉGICAS Y RAZONES OPERATIVAS PARA LA COOPERACIÓN ENTRE EMPRESAS}

En el estricto sentido del ámbito productivo, Isaksen (1998), Shoengen (2001), Bremen, et.al. (2005) y Karlsson (2007), entre otros, identificaron que los clusters pueden ser definidos como un agrupamiento o concentración de empresas 0 agentes interdependientes en un espacio geográfico determinado y que tiene la finalidad de crear un sistema de producción local o de un sistema social. En la literatura especializada los expertos han denominado a las asociaciones entre agentes (generalmente empresas) con diversos nombres, como el de distrito industrial (creado por Alfred Marshall), polo de desarrollo, encadenamientos productivos, redes de trabajo y el más popular entre los economistas contemporáneos, clusters. Marshall, en su Industry and Trade (Industria y Comercio, de 1919) concibió al distrito industrial como una evolución natural del mercado, caracterizado por un ambiente de información tácita compartida entre los miembros de una comunidad geográficamente identificable. Estas observaciones llevaron a 
Llamazares, Francisco y Berumen, Sergio A. Cooperar para competir: la cooperación entre empresas como estrategia para el fomento de la competitividad.

generar los conceptos de economías externas a las empresas y a las industrias, y que la presencia o ausencia de estas economías externas tenía una fuerte influencia sobre el éxito o fracaso de empresas y sectores industriales. El concepto de Polo de Desarrollo fue creado con la intención de potenciar esas economías externas por medio de la intervención gubernamental, y de ese modo atraer la inversión de empresas a determinados giros industriales ubicados en zonas geográficas específicas. Era tarea de los gobiernos el establecimiento del giro industrial inicial o base del polo, procurando que éste presentara las características de un monopolio natural (economías crecientes a escala estáticas). ${ }^{1}$

Dessy (2007) ha estudiado que la conformación de clusters permite a los agentes participantes una serie de ventajas que de forma aislada difícilmente se podrían alcanzar; estas ventajas son un aliciente adicional que tienen los agentes para cooperar, aunque en particular se destaca la potenciación de la competitividad. Mediante la conformación de clusters a los agentes les es posible lograr una mayor flexibilidad y la eventualidad para obtener nuevos conocimientos e información respecto a las actividades que conforman la cadena de valor (ver Nadvi y Halder, 2005). Las razones para concretar los clusters pueden ser estratégicas y operativas, como se muestra en el siguiente cuadro.

\section{Cuadro 2. Razones Estratégicas y Razones Operativas para la conformación de} clusters.

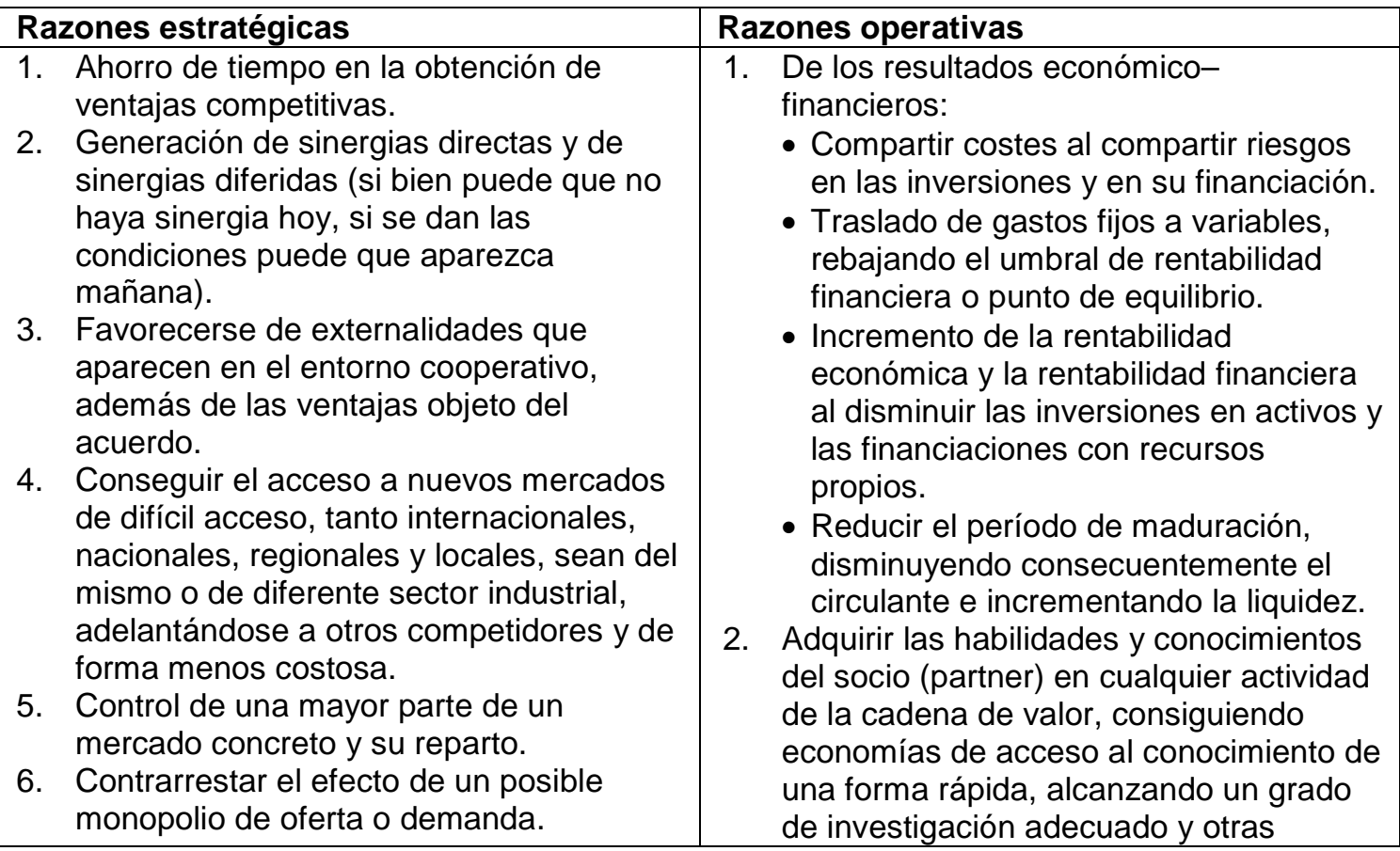

\footnotetext{
${ }^{1}$ Como lo señalan Ionita, Ursacescu y Burlacu (2009), los abusos cometidos en el uso del concepto de Polo de Desarrollo, originalmente creado por Hansen (1963), y los frecuentes fracasos derivados de estos excesos, llevaron a un extremo igualmente peligroso en la década de los setenta, al considerar que: i) cualquier resultado de la libre operación del mercado es óptimo; ii) las empresas son competitivas por sí solas; y iii), que las economías externas (de aglomeración y de concentración) no existen o, de existir, su efecto es marginal o insignificante. Algunas de las principales lecciones de la variada interpretación del concepto han sido:

- Los excesos en la aplicación de una medida conllevan a una reacción igualmente poderosa en sentido contrario.

- Esta sobre-reacción provoca la pérdida de conocimientos adquiridos, frecuentemente no recuperables. Esta pérdida de conocimiento puede conducir a cometer excesos igualmente graves, pero de signo contrario, con lo cual, se cierra el ciclo.
} 
Llamazares, Francisco y Berumen, Sergio A. Cooperar para competir: la cooperación entre empresas como estrategia para el fomento de la competitividad.

\begin{tabular}{|c|c|}
\hline $\begin{array}{l}\text { 7. Disminuir la concurrencia para alcanzar } \\
\text { una posición dominante. } \\
\text { 8. Mantenimiento de la flexibilidad de la } \\
\text { organización (por no necesitar de una } \\
\text { estructura pesada, de activos materiales } \\
\text { o de personal), por utilizar una misma } \\
\text { tecnología. } \\
\text { 9. Posibilitar un mejor acceso a las fuentes } \\
\text { de financiación. } \\
\text { 10. Reconvertir un sector determinado, } \\
\text { mediante la racionalización y } \\
\text { modernización de las instalaciones } \\
\text { productivas, adecuando las capacidades } \\
\text { de producción y los precios. } \\
\text { 11. Adoptar una medida de fuerza ante los } \\
\text { poderes públicos. } \\
\text { 12. Facilidad para conseguir bonificaciones, } \\
\text { exenciones fiscales y subvenciones. } \\
\text { 13. Equilibrio de resultados, cuando se } \\
\text { asocian empresas a las que les afecta de } \\
\text { forma diferente la evolución del ciclo } \\
\text { económico. } \\
\text { 14. Equilibrio de resultados, cuando se } \\
\text { asocian empresas con productos en } \\
\text { diferentes etapas del ciclo de vida. } \\
\text { 15. Aprendizaje del proceso de cooperación }\end{array}$ & $\begin{array}{l}\text { ventajas a lo largo de la cadena. } \\
\text { 3. Lograr economías de escala y de } \\
\text { experiencia por incremento de la } \\
\text { producción-comercialización de los } \\
\text { agentes participantes, bien sea a través } \\
\text { de la especialización (acuerdos } \\
\text { verticales) o por ser conjunta (acuerdos } \\
\text { horizontales). } \\
\text { 4. Consecución de economías de alcance, } \\
\text { al compartir algún tipo de recursos, } \\
\text { ahorrando inversiones. } \\
\text { 5. Mejorar las condiciones respecto a } \\
\text { competidores o clientes y a proveedores } \\
\text { al haber aumentado el poder de } \\
\text { mercado. } \\
\text { 6. Fiabilidad en el suministro de inputs y a } \\
\text { precio más reducido. } \\
\text { 7. Aseguramiento de la calidad de los } \\
\text { inputs. } \\
\text { 8. Reducción de los volúmenes de } \\
\text { existencias. } \\
\text { 9. Control sobre la distribución del producto } \\
\text { final. } \\
\text { 10. Crear una infraestructura de distribución. }\end{array}$ \\
\hline
\end{tabular}

En virtud de lo anteriormente señalado, los clusters consisten en: i) un grupo coordinado de agentes que pertenecen al mismo o a diferentes sectores productivos; ii) que desarrollan diferentes niveles de la cadena de producción o de servicios complementarios; iii) o que desempeñan labores diversas al ámbito empresarial, como el sector gubernamental o de la generación de conocimientos, como las universidades y los centros de investigación; y iv), que en lo individual ostentan diferentes habilidades $\mathrm{y} / \mathrm{o}$ conocimientos o que poseen una particular base de un mismo segmento de la demanda en un mercado específico, entre otros aspectos. La conformación de clusters comprende la consolidación de la información compartida entre los participantes, lo cual implica la necesidad de desarrollar códigos de lenguaje comunes y canales de comunicación que permitan el adecuado flujo del conocimiento. Los objetivos de la conformación de clusters son múltiples; algunos de los principales son:

- Concretar o consolidar las fuentes de oferta o demanda.

- Mayor flujo de transferencia de tecnología de una empresa a otra.

- Complementariedad tecnológica entre las empresas participantes.

- Economías de escala y alcance (en la producción a otros campos).

- Comercialización de productos. 
Llamazares, Francisco y Berumen, Sergio A. Cooperar para competir: la cooperación entre empresas como estrategia para el fomento de la competitividad.

- La especialización en habilidades concretas.

- Incrementar la flexibilidad y las fortalezas.

- Diversificar el riesgo.

- Potenciar las ventajas y los conocimientos.

- La reducción de costes.

Con posterioridad a la obtención de los objetivos, los clusters pueden sobrevivir si constantemente se plantean nuevos retos, o bien desaparecer (Cooke, 2001 y Brett et.al 2008). Los clusters de tipo industrial están constituidos por una estructura institucional que rige a la organización eficiente de las actividades económicas, y que lo hace a través de la coordinación de los vínculos sistemáticos que se establecen entre las empresas participantes en las cadenas de producción. Este tipo de sistemas únicamente operan apropiadamente cuando están respaldadas por convenciones, hábitos y reglas no escritas. En el cuadro 3 se exponen las condiciones ambientales que favorecen o determinan la formación de clusters.

Cuadro 3. Condiciones ambientales para la conformación de clusters.

\begin{tabular}{|c|c|c|}
\hline & $\begin{array}{l}\text { Alto potencial para la concreción } \\
\text { de clusters }\end{array}$ & $\begin{array}{l}\text { Bajo potencial para la concreción } \\
\text { de clusters }\end{array}$ \\
\hline $\begin{array}{l}\text { A Nivel Meta- } \\
\text { Económico }\end{array}$ & $\begin{array}{ll}\checkmark & \text { Cultura cooperativa. } \\
\checkmark & \text { Aprendizaje interactivo. } \\
\checkmark & \text { Asociación por consenso. }\end{array}$ & $\begin{array}{l}\checkmark \text { Cultura individualista y } \\
\text { competitiva. } \\
\text { Instituciones proclives al disenso. }\end{array}$ \\
\hline $\begin{array}{l}\text { A Nivel Macro- } \\
\text { Económico }\end{array}$ & $\begin{array}{l}\quad \text { Autonomía para el ejercicio y } \\
\text { gasto de los recursos económicos. } \\
\checkmark \quad \text { Instituciones privadas a nivel } \\
\text { local y en los aspectos financieros. } \\
\checkmark \quad \text { Influencia local en la aplicación } \\
\text { y seguimiento de las políticas de la } \\
\text { infraestructura. } \\
\checkmark \quad \text { Estrategias locales entre las } \\
\text { industrias y las universidades. }\end{array}$ & $\begin{array}{l}\checkmark \text { Centralización en el ejercicio y } \\
\text { gasto de los recursos económicos. } \\
\checkmark \text { Organizaciones financieras a nivel } \\
\text { nacional. } \\
\checkmark \text { Una limitada influencia local de } \\
\text { las políticas de infraestructura. } \\
\checkmark \text { Pobres o nulas políticas de } \\
\text { innovación. }\end{array}$ \\
\hline $\begin{array}{l}\text { A Nivel Micro- } \\
\text { Económico }\end{array}$ & $\begin{array}{l}\checkmark \text { Relaciones laborales } \\
\text { armoniosas. } \\
\checkmark \text { Trabajo dirigido y coordinado. } \\
\checkmark \text { Exteriorizan sus problemas. } \\
\checkmark \text { Investigación, desarrollo e } \\
\text { innovación interactiva y dispuesta a } \\
\text { ser compartida. }\end{array}$ & $\begin{array}{l}\checkmark \text { Relaciones laborales que tienden } \\
\text { al disenso y a la confrontación. } \\
\checkmark \text { Competencias individuales y con } \\
\text { resistencia a compartirlas. } \\
\checkmark \quad \text { Interiorizan los problemas. } \\
\checkmark \text { Investigación, desarrollo e } \\
\text { innovación privativa y no dispuesta a } \\
\text { ser compartida. }\end{array}$ \\
\hline $\begin{array}{l}\text { A Nivel de la } \\
\text { Política } \\
\text { Organizacional }\end{array}$ & $\begin{array}{ll}\checkmark & \text { Incluyente. } \\
\checkmark & \text { Monitoreo. } \\
\checkmark & \text { Consultante. }\end{array}$ & $\begin{array}{ll}\checkmark & \text { Excluyente. } \\
\checkmark & \text { Reactiva. } \\
\checkmark & \text { Imperativa. } \\
\checkmark & \text { Jerárquica. }\end{array}$ \\
\hline
\end{tabular}

La coordinación de esfuerzos en inversión, y particularmente en el diseño, investigación, desarrollo e innovación, frecuentemente requiere de un constante e 
Llamazares, Francisco y Berumen, Sergio A. Cooperar para competir: la cooperación entre empresas como estrategia para el fomento de la competitividad.

intenso contacto entre los agentes. La coordinación de una política tecnológica dinámica es la mayor ventaja de los clusters, de modo que las industrias dinámicas en el uso, desarrollo e implantación de tecnología ofrecen grandes oportunidades para la conformación de clusters productivos. Hay un proceso de coevolución entre las características de los regímenes tecnológicos, las estrategias tecnológicas adoptadas por las empresas, así como de los clusters orientados a la aceleración de los procesos de innovación.

Se pueden identificar tres características de los regímenes tecnológicos que pueden impactar negativamente en el desarrollo de los clusters: i) la falta de acumulación de conocimiento tecnológico en cada régimen; ii) las condiciones adecuadas para la generación y asimilación de las innovaciones; y, iii) las características del conocimiento relevante que deben ser aprovechadas para generar innovaciones tecnológicas. Asimismo, los clusters pueden ser clasificados de acuerdo a la complejidad de los sistemas tecnológicos en los términos de: i) la arquitectura de productos y de la interconectividad de las actividades de producción; y ii), en la complejidad de los regímenes tecnológicos en los términos de la diversidad del conocimiento y de las competencias y habilidades necesarias. El adecuado uso de ambos criterios permite crear cuatro tipos diferentes de clusters: i) tradicionales, basados en la subcontratación; ii) de trabajo, basados en el ensamblaje modular; iii) basados en productos complejos; y iv), basados en la investigación, desarrollo, innovación e implantación de la tecnología. En el siguiente cuadro se muestran las principales características de los clusters de acuerdo a su tipología.

Cuadro 4. Características de los clusters.

\begin{tabular}{|c|c|c|c|c|}
\hline & $\begin{array}{c}\text { Clusters } \\
\text { tradicionales, } \\
\text { basados en la } \\
\text { subcontratación }\end{array}$ & $\begin{array}{c}\text { Clusters basados } \\
\text { en el ensamblaje } \\
\text { modular }\end{array}$ & $\begin{array}{l}\text { Clusters basados } \\
\text { en productos } \\
\text { complejos }\end{array}$ & $\begin{array}{c}\text { Clusters basados en } \\
\text { la I+D+i e } \\
\text { implantación de la } \\
\text { tecnología }\end{array}$ \\
\hline $\begin{array}{l}\text { Principales } \\
\text { características }\end{array}$ & $\begin{array}{l}\text { Especialización } \\
\text { funcional de } \\
\text { los insumos en } \\
\text { los diversos } \\
\text { niveles del } \\
\text { proceso de } \\
\text { producción. } \\
\checkmark \quad \text { La fuente } \\
\text { principal del } \\
\text { progreso } \\
\text { tecnológico } \\
\text { proviene de } \\
\text { fuera del } \\
\text { cluster. }\end{array}$ & 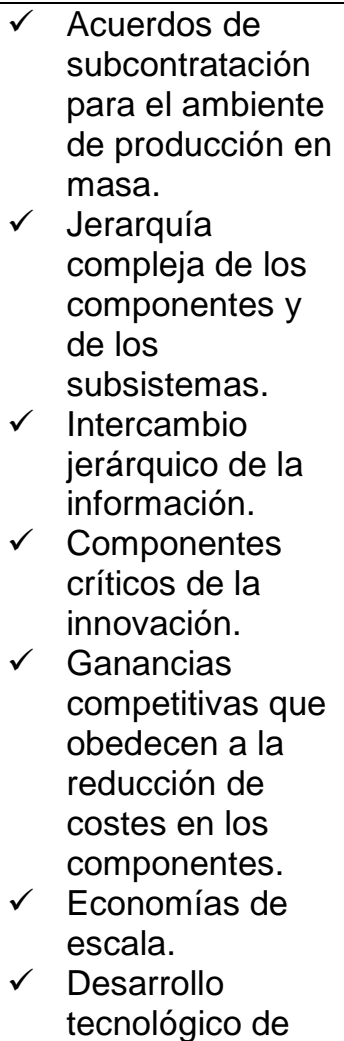 & $\begin{array}{ll}\checkmark & \text { Organizada en } \\
\text { base a un } & \text { proyecto } \\
\text { específico. } \\
\checkmark \quad \text { Producción de } \\
\text { alto valor (v.g. } \\
\text { ingeniería } \\
\text { intensiva), y los } \\
\text { productos } \\
\text { orientados al } \\
\text { cliente. } \\
\text { Sufren de } \\
\text { pequeños } \\
\text { problemas } \\
\text { constantement } \\
\text { e. } \\
\text { Competitividad } \\
\text { basada en un } \\
\text { alto } \\
\text { rendimiento en } \\
\text { la solución de } \\
\text { demandas } \\
\text { específicas } \\
\text { para clientes } \\
\text { con } \\
\text { necesidades }\end{array}$ & $\begin{array}{ll}\checkmark & \text { Desarrollo de } \\
\text { productos basados } & \text { en nuevas } \\
\text { tecnologías. } \\
\checkmark \quad \text { Integración basada } \\
\text { en conocimientos } \\
\text { complejos. } \\
\checkmark \quad \text { Destacada } \\
\text { importancia y } \\
\text { financiación de la } \\
\text { I+D+i. } \\
\text { Baja complejidad } \\
\text { de las actividades } \\
\text { de producción. } \\
\text { Ganancia basada } \\
\text { en la integración de } \\
\text { habilidades } \\
\text { complementarias. } \\
\text { Alta horizontalidad } \\
\text { y baja verticalidad } \\
\text { en el intercambio } \\
\text { de información. } \\
\text { Las propiedades } \\
\text { del producto están } \\
\text { definidas por una } \\
\text { base de }\end{array}$ \\
\hline
\end{tabular}


Llamazares, Francisco y Berumen, Sergio A. Cooperar para competir: la cooperación entre empresas como estrategia para el fomento de la competitividad.

\begin{tabular}{|c|c|c|c|c|}
\hline & & $\begin{array}{l}\text { productos } \\
\text { basado en un } \\
\text { incremento } \\
\text { modular. }\end{array}$ & $\begin{array}{ll} & \text { sofisticadas. } \\
\checkmark & \text { Usuarios que } \\
& \text { se implican en } \\
& \text { el desarrollo. } \\
\checkmark & \text { Innovación } \\
\text { basada en } \\
\text { relaciones } \\
\text { complejas } \\
\text { entre los } \\
\text { sistemas semi- } \\
\text { autónomos. } \\
\checkmark \text { Integración en } \\
\text { diversas bases } \\
\text { de } \\
\text { conocimiento. } \\
\text { Reducción de } \\
\text { costes y } \\
\text { tiempo a través } \\
\text { de la } \\
\text { implantación } \\
\text { de procesos de } \\
\text { ingeniería } \\
\text { paralelos }\end{array}$ & $\begin{array}{l}\text { interacciones } \\
\text { recíprocas y de } \\
\text { mecanismos de } \\
\text { aprendizaje entre } \\
\text { productores, } \\
\text { proveedores y } \\
\text { clientes. }\end{array}$ \\
\hline $\begin{array}{l}\text { Flujos } \\
\text { materiales }\end{array}$ & 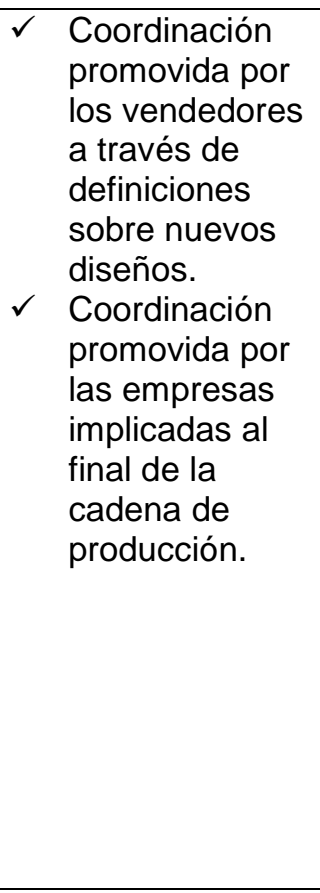 & $\begin{array}{l}\checkmark \text { Implantación de } \\
\text { protocolos } \\
\text { basados en los } \\
\text { principios del } \\
\text { just-in-time } \\
\text { (entrega a } \\
\text { tiempo). } \\
\checkmark \quad \text { Proyectos } \\
\text { orientados al co- } \\
\text { desarrollo de } \\
\text { nuevos } \\
\text { componentes y } \\
\text { sub-sistemas } \\
\text { entre los } \\
\text { ensambladores y } \\
\text { los proveedores. }\end{array}$ & $\begin{array}{ll} & \text { Técnicas } \\
\text { específicas } \\
\text { para la gestión } \\
\text { de proyectos. } \\
\checkmark \quad \text { Uso intensivo } \\
\text { en la } \\
\text { coordinación } \\
\text { de } \\
\text { mecanismos } \\
\text { no basados en } \\
\text { el mercado, } \\
\text { sino en } \\
\text { acuerdos de } \\
\text { cooperación } \\
\text { ex-ante. } \\
\text { Técnicas de } \\
\text { negociación } \\
\text { entre los } \\
\text { niveles de } \\
\text { diseño, } \\
\text { desarrollo y } \\
\text { manufactura. }\end{array}$ & $\bar{\checkmark}$ \\
\hline $\begin{array}{l}\text { Flujos de } \\
\text { información }\end{array}$ & $\begin{array}{ll}\checkmark & \text { No hay } \\
\text { intercambio } \\
\text { sistemático de } \\
\text { la información } \\
\text { sobre las } \\
\text { mejoras y } \\
\text { calidad de los } \\
\text { componentes. } \\
\checkmark \quad \text { Los flujos de la } \\
\text { información } \\
\text { tienden a } \\
\text { asumir que } \\
\text { ésta siempre }\end{array}$ & $\begin{array}{ll}\checkmark & \text { El flujo de la } \\
\text { información } \\
\text { asume un } \\
\text { carácter en dos } \\
\text { vías. } \\
\checkmark \quad \text { Uso intensivo de } \\
\text { la informática (en } \\
\text { especial de las } \\
\text { telecomunicacion } \\
\text { es). } \\
\checkmark \quad \text { Desarrollo de } \\
\text { códigos } \\
\text { específicos de }\end{array}$ & $\begin{array}{ll}\checkmark & \text { Los usuarios } \\
\text { se implican } \\
\text { intensivamente } \\
\text { en el afán de } \\
\text { definir sus } \\
\text { necesidades y } \\
\text { de optimizar el } \\
\text { producto. } \\
\checkmark \quad \text { Intenso } \\
\text { intercambio de } \\
\text { información } \\
\text { sobre las } \\
\text { propiedades de }\end{array}$ & $\begin{array}{l}\checkmark \text { Usualmente son } \\
\text { complejos, e } \\
\text { implica una } \\
\text { retroalimentación } \\
\text { entre los } \\
\text { participantes y } \\
\text { niveles de la I+D+i. } \\
\checkmark \quad \text { El flujo se basa en } \\
\text { las relaciones inter- } \\
\text { personales e inter- } \\
\text { grupales, a través } \\
\text { de dicha } \\
\text { transmisión se }\end{array}$ \\
\hline
\end{tabular}


Llamazares, Francisco y Berumen, Sergio A. Cooperar para competir: la cooperación entre empresas como estrategia para el fomento de la competitividad.

\begin{tabular}{|c|c|c|c|c|c|c|}
\hline & $\begin{array}{l}\text { viene de los } \\
\text { vendedores y } \\
\text { de las } \\
\text { empresas que } \\
\text { se dedican al } \\
\text { ensamblaje. }\end{array}$ & & comunicación. & $\begin{array}{ll} & \text { los } \\
& \text { subsistemas. } \\
\checkmark & \text { Flujo de la } \\
\text { información a } \\
\text { través de dos } \\
\text { vías, y } \\
\text { tendiente a } \\
\text { integrar } \\
\text { recursos } \\
\text { intangibles. } \\
\text { Asistencia } \\
\text { técnica entre } \\
\text { usuarios y } \\
\text { entre los } \\
\text { sistemas } \\
\text { integrados. }\end{array}$ & & $\begin{array}{l}\text { puede generar } \\
\text { conocimiento tácito. }\end{array}$ \\
\hline $\begin{array}{l}\text { Complejidad } \\
\text { tecnológica }\end{array}$ & $\begin{array}{ll}\checkmark & \text { Baja } \\
& \text { complejidad. } \\
\checkmark & \text { Simplicidad en } \\
& \text { la base de } \\
& \text { conocimientos. } \\
\checkmark & \text { Altos } \\
& \text { márgenes de } \\
& \text { tolerancia en } \\
\text { términos de los } \\
\text { procedimientos } \\
\text { productivos y } \\
\text { de los niveles } \\
\text { de calidad. }\end{array}$ & $\checkmark$ & $\begin{array}{l}\text { Alto nivel, altos } \\
\text { volúmenes, alta } \\
\text { variedad y alta } \\
\text { complejidad } \\
\text { técnica. } \\
\text { Diseños } \\
\text { complejos } \\
\text { basados en } \\
\text { mecanismos } \\
\text { lineares de } \\
\text { vinculación. } \\
\text { Arquitectura } \\
\text { modular que } \\
\text { permite } \\
\text { diferentes } \\
\text { combinaciones } \\
\text { de los } \\
\text { componentes y } \\
\text { de sub- } \\
\text { ensamblaje con } \\
\text { la utilización de } \\
\text { plataformas } \\
\text { similares }\end{array}$ & $\begin{aligned} \checkmark & \text { Altos niveles } \\
& \text { de } \\
& \text { complejidad. } \\
\checkmark & \text { Extremo e } \\
& \text { intensivo en } \\
& \text { ingeniería. } \\
\checkmark & \text { Arquitectura no } \\
& \text { linear. } \\
\checkmark & \text { Bajos } \\
& \text { márgenes de } \\
& \text { tolerancia. }\end{aligned}$ & $\begin{array}{l}\checkmark \\
\checkmark\end{array}$ & $\begin{array}{l}\text { La complejidad de } \\
\text { la producción } \\
\text { tecnológica de la } \\
\text { producción es } \\
\text { relativamente baja. } \\
\text { Productos con un } \\
\text { alto valor pero de } \\
\text { un bajo volumen. } \\
\text { Sustentada en altos } \\
\text { e intensivos } \\
\text { esfuerzos de I+D+i. }\end{array}$ \\
\hline $\begin{array}{l}\text { Aprendizaje } \\
\text { interactivo }\end{array}$ & $\begin{array}{l}\checkmark \text { Esfuerzo de las } \\
\text { competencias } \\
\text { que permiten } \\
\text { una mejora de } \\
\text { los productos y } \\
\text { los } \\
\text { componentes. } \\
\checkmark \quad \text { Difusión de } \\
\text { mayores } \\
\text { estándares de } \\
\text { sofisticación } \\
\text { técnica y de } \\
\text { controles y } \\
\text { procedimientos } \\
\text { más rígidos. }\end{array}$ & $\checkmark$ & $\begin{array}{l}\text { Mejoras } \\
\text { continuas de los } \\
\text { componentes } \\
\text { existentes. } \\
\text { Desarrollo de } \\
\text { nuevos } \\
\text { componentes y } \\
\text { subsistemas para } \\
\text { ser incorporados } \\
\text { en la arquitectura } \\
\text { existente } \\
\text { Desarrollo de } \\
\text { nuevas } \\
\text { variedades de } \\
\text { productos } \\
\text { basadas en la } \\
\text { misma } \\
\text { arquitectura. } \\
\text { Redefiniciones }\end{array}$ & $\begin{array}{ll} & \text { Adaptación de } \\
& \text { productos de } \\
& \text { acuerdo a las } \\
\text { necesidades } & \\
\text { de los } & \text { compradores. } \\
& \text { Reforzamiento } \\
& \text { de las } \\
\text { competencias } \\
\text { de los sistemas } \\
\text { integrados. } \\
\checkmark \quad \text { La } \\
\text { consolidación } \\
\text { de los } \\
\text { mercados no } \\
\text { debe basarse } \\
\text { en complejas } \\
\text { transacciones. }\end{array}$ & $\begin{array}{l}\checkmark \\
\checkmark\end{array}$ & $\begin{array}{l}\text { División del trabajo } \\
\text { en términos de } \\
\text { esfuerzos } \\
\text { innovadores. } \\
\text { Conexiones más } \\
\text { estrechas entre la } \\
\text { tecnología de base } \\
\text { y los usuarios } \\
\text { finales de las } \\
\text { empresas. } \\
\text { Definiciones de } \\
\text { apropiabilidad. } \\
\text { Definiciones de } \\
\text { códigos de } \\
\text { lenguaje entre los } \\
\text { diferentes campos } \\
\text { cognitivos del } \\
\text { conocimiento. }\end{array}$ \\
\hline
\end{tabular}


Llamazares, Francisco y Berumen, Sergio A. Cooperar para competir: la cooperación entre empresas como estrategia para el fomento de la competitividad.

\begin{tabular}{|c|c|c|c|c|}
\hline & & $\begin{array}{l}\text { periódicas y } \\
\text { adaptaciones de } \\
\text { la arquitectura a } \\
\text { las nuevas } \\
\text { necesidades. }\end{array}$ & & \\
\hline $\begin{array}{l}\text { Esfuerzos } \\
\text { orientados a la } \\
\text { generación de } \\
\text { innovaciones }\end{array}$ & $\begin{array}{ll}\checkmark & \text { No sistémicos. } \\
\checkmark & \text { Innovación } \\
& \text { incremental. } \\
\checkmark & \text { Centralización } \\
& \text { de las } \\
& \text { actividades de } \\
& \text { diseño en las } \\
& \text { empresas } \\
& \text { ensambladoras } \\
& \text { o en los } \\
& \text { vendedores. }\end{array}$ & $\begin{array}{ll} & \text { "Innovaciones } \\
& \text { programadas". } \\
\checkmark & \text { Componentes } \\
& \text { hechos por } \\
\text { proveedores en } \\
\text { coordinación con } \\
\text { los } \\
\text { ensambladores. }\end{array}$ & $\begin{array}{ll} & \text { Interfaces } \\
\text { complejas } & \text { entre } \\
\text { proveedores y } & \\
\text { usuarios. } \\
\checkmark \text { Compatibilizar } \\
\text { el marketing } \\
\text { con los } \\
\text { atributos } \\
\text { técnicos } \\
\text { orientados a } \\
\text { diversos } \\
\text { componentes. } \\
\text { Cambios en las } \\
\text { formas de los } \\
\text { componentes y } \\
\text { subsistemas } \\
\text { de modo que } \\
\text { formen una } \\
\text { arquitectura del } \\
\text { producto. } \\
\text { Rutas } \\
\text { innovadoras } \\
\text { orientadas a } \\
\text { lograr } \\
\text { acuerdos ex- } \\
\text { ante. }\end{array}$ & $\begin{array}{l}\text { Interdisciplinariedad } \\
\text { de los procesos de } \\
\text { I+D+i en base a } \\
\text { fuertes } \\
\text { interconexiones } \\
\text { entre los } \\
\text { tecnólogos y las } \\
\text { infraestructuras } \\
\text { científicas. }\end{array}$ \\
\hline Gobernabilidad & $\begin{array}{l}\text { Estructuras } \\
\text { dispersas con } \\
\text { un bajo nivel } \\
\text { de } \\
\text { jerarquización } \\
\text { que abarque } \\
\text { todo el sistema } \\
\text { integralmente. }\end{array}$ & $\begin{array}{l}\text { Basado en un rol } \\
\text { central, } \\
\text { optimizado por } \\
\text { un equipo de } \\
\text { expertos en los } \\
\text { temas de los } \\
\text { clusters. } \\
\checkmark \quad \text { Jerarquización de } \\
\text { los proveedores } \\
\text { del subsistema y } \\
\text { de los } \\
\text { componentes de } \\
\text { acuerdo con el } \\
\text { manejo técnico y } \\
\text { con la intensidad } \\
\text { de la interacción } \\
\text { con las cabezas } \\
\text { de los } \\
\text { ensambladores. }\end{array}$ & $\begin{array}{ll}\checkmark & \text { Sistema } \\
& \text { integrador y de } \\
& \text { sus } \\
& \text { proveedores. } \\
\checkmark & \text { Estructura de } \\
& \text { gobierno } \\
& \text { relativamente } \\
& \text { flexible basada } \\
\text { en proyectos } \\
\text { específicos. } \\
\checkmark \quad \text { Jerarquización } \\
\text { de acuerdo a } \\
\text { los } \\
\text { subsistemas y } \\
\text { sus } \\
\text { componentes. }\end{array}$ & $\begin{array}{l}\text { Basado en la } \\
\text { definición de tareas } \\
\text { de acuerdo a los } \\
\text { requerimientos } \\
\text { orientados a las } \\
\text { diferentes etapas } \\
\text { del proceso de } \\
\text { I+D+i. } \\
\text { Coordinación de las } \\
\text { relaciones inter- } \\
\text { clusters para que } \\
\text { fluyan en tres vías: } \\
\text { i) inducción a los } \\
\text { usuarios; ii) la } \\
\text { tecnología basada } \\
\text { en acuerdos entre } \\
\text { empresas; o, iii) } \\
\text { consolidación a } \\
\text { partir de un } \\
\text { acuerdo previo. } \\
\text { Alta certidumbre. } \\
\text { La compenetración } \\
\text { entre los dueños de } \\
\text { los derechos } \\
\text { tecnológicos y los } \\
\text { usuarios finales }\end{array}$ \\
\hline
\end{tabular}


Llamazares, Francisco y Berumen, Sergio A. Cooperar para competir: la cooperación entre empresas como estrategia para el fomento de la competitividad.

\begin{tabular}{|l|l|l|l|}
\hline & & & $\begin{array}{l}\text { permite mantener } \\
\text { incentivos y } \\
\text { relaciones basadas } \\
\text { en la cooperación. }\end{array}$ \\
\hline
\end{tabular}

Fuente: elaboración propia a partir de De Propris (2006).

Cuadro 5. Clasificación tecnológica de las empresas en base a sus actividades económicas.

\begin{tabular}{|c|c|c|c|c|c|c|}
\hline & $\begin{array}{l}\text { Intensivas en el } \\
\text { uso de recursos } \\
\text { naturales }\end{array}$ & $\begin{array}{l}\text { Abastecedores } \\
\text { predominantes } \\
\text { de la Oferta }\end{array}$ & Escala Intensiva & $\begin{array}{l}\text { Información } \\
\text { Intensiva }\end{array}$ & $\begin{array}{l}\text { Especializadas } \\
\text { en la Oferta }\end{array}$ & $\begin{array}{l}\text { Conocimiento } \\
\text { Intensivo }\end{array}$ \\
\hline Sector industrial & $\begin{array}{l}\text { Agricultura. } \\
\text { Minería. } \\
\text { Pesca. }\end{array}$ & $\begin{array}{l}\text { Construcción. } \\
\text { Venta al } \\
\text { menudeo. } \\
\text { Manufactura de } \\
\text { ropa y textiles }\end{array}$ & $\begin{array}{l}\text { Vehículos y sus } \\
\text { componentes. } \\
\text { Manufactura del } \\
\text { acero. } \\
\text { Ingeniería civil }\end{array}$ & $\begin{array}{l}\text { Finanzas. } \\
\text { Publicidad. } \\
\text { Servicios de } \\
\text { transporte }\end{array}$ & $\begin{array}{l}\text { Fabricación de } \\
\text { maquinaria } \\
\text { pesada. } \\
\text { Software. }\end{array}$ & $\begin{array}{l}\text { Micro-electrónica } \\
\text { y nanotecnología, } \\
\text { química y } \\
\text { farmacéutica, } \\
\text { aeronáutica y } \\
\text { aeroespacial. } \\
\text { Nuevos } \\
\text { materiales. } \\
\text { Genética y } \\
\text { biología. }\end{array}$ \\
\hline $\begin{array}{l}\text { Tamaño de la } \\
\text { empresa }\end{array}$ & Variable & Pequeña & Grande & Grande & Pequeña & Grande \\
\hline Tipo de usuarios & $\begin{array}{l}\text { Sensible a los } \\
\text { precio }\end{array}$ & $\begin{array}{l}\text { Sensible a los } \\
\text { precios }\end{array}$ & Mezcla & Mezcla & $\begin{array}{l}\text { Mejoradora de } \\
\text { precios }\end{array}$ & Mezcla \\
\hline $\begin{array}{l}\text { Principal centro } \\
\text { de actividades } \\
\text { tecnológicas }\end{array}$ & $\begin{array}{l}\text { Reductora de } \\
\text { costes }\end{array}$ & $\begin{array}{l}\text { Reductora de } \\
\text { precios }\end{array}$ & Mezcla & Mezcla & $\begin{array}{l}\text { Mejoradora de } \\
\text { productos }\end{array}$ & Mezcla \\
\hline $\begin{array}{l}\text { Principales } \\
\text { fuentes de } \\
\text { acumulación } \\
\text { tecnológica }\end{array}$ & $\begin{array}{l}\text { Abastecedora } \\
\text { Aprende de la } \\
\text { producción. } \\
\text { Proveedora de } \\
\text { servicios }\end{array}$ & $\begin{array}{l}\text { Abastecedora. } \\
\text { Aprende de la } \\
\text { producción. } \\
\text { Proveedora de } \\
\text { servicios }\end{array}$ & $\begin{array}{l}\text { Aprende de la } \\
\text { producción. } \\
\text { Proveedora. }\end{array}$ & $\begin{array}{l}\text { Sistemas } \\
\text { corporativos } \\
\text { de software y } \\
\text { de la } \\
\text { ingeniería. } \\
\text { Equipamiento } \\
\text { de software. } \\
\text { Ingeniería y } \\
\text { diseño. } \\
\end{array}$ & $\begin{array}{l}\text { Diseño y } \\
\text { desarrollo. } \\
\text { Usuarios } \\
\text { especializados. }\end{array}$ & $\begin{array}{l}\text { I+D+i de forma } \\
\text { cooperativa. } \\
\text { Investigación } \\
\text { básica. } \\
\text { Orientada a la } \\
\text { producción. }\end{array}$ \\
\hline $\begin{array}{l}\text { Principal forma } \\
\text { de administración } \\
\text { y gestión de la } \\
\text { acumulación } \\
\text { tecnológica }\end{array}$ & $\begin{array}{l}\text { Orientada al } \\
\text { proceso } \\
\text { tecnológico y al } \\
\text { equipamiento } \\
\text { constante. }\end{array}$ & $\begin{array}{l}\text { Orientada al } \\
\text { proceso } \\
\text { tecnológico y al } \\
\text { equipamiento } \\
\text { constante. }\end{array}$ & $\begin{array}{l}\text { Orientada al } \\
\text { proceso } \\
\text { tecnológico y al } \\
\text { constante } \\
\text { equipamiento. }\end{array}$ & $\begin{array}{l}\text { Orientada al } \\
\text { proceso } \\
\text { tecnológico y } \\
\text { al software. }\end{array}$ & $\begin{array}{l}\text { Mejoradora de } \\
\text { productos. }\end{array}$ & $\begin{array}{l}\text { Orientada al } \\
\text { desarrollo } \\
\text { tecnológico de } \\
\text { productos. }\end{array}$ \\
\hline $\begin{array}{l}\text { Principales } \\
\text { canales de } \\
\text { imitación y } \\
\text { transferencia de } \\
\text { tecnología }\end{array}$ & $\begin{array}{l}\text { Compradora de } \\
\text { equipo y de } \\
\text { servicios } \\
\text { relacionados. }\end{array}$ & $\begin{array}{l}\text { Compradora de } \\
\text { equipo y de } \\
\text { servicios } \\
\text { relacionados. }\end{array}$ & $\begin{array}{l}\text { Compradora de } \\
\text { equipo, de } \\
\text { licencias de } \\
\text { know-how y de } \\
\text { entrenamiento } \\
\text { relacionado. }\end{array}$ & $\begin{array}{l}\text { Compradora } \\
\text { de equipo y } \\
\text { software. }\end{array}$ & $\begin{array}{l}\text { Aprende de las } \\
\text { experiencias de } \\
\text { los usuarios } \\
\text { más avanzados. }\end{array}$ & $\begin{array}{l}+\mathrm{D}+\mathrm{i} \text { y está } \\
\text { permanentemente } \\
\text { vinculada con } \\
\text { ingenieros y } \\
\text { científicos. }\end{array}$ \\
\hline $\begin{array}{l}\text { Principales } \\
\text { métodos de } \\
\text { protección contra } \\
\text { la imitación ilegal }\end{array}$ & Ninguno & $\begin{array}{l}\text { No de tipo } \\
\text { técnico, tales } \\
\text { como marketing } \\
\text { y registro de } \\
\text { derechos de } \\
\text { propiedad. }\end{array}$ & $\begin{array}{l}\text { Secreto en el } \\
\text { proceso. } \\
\text { Diseño y } \\
\text { operación de } \\
\text { know-how. }\end{array}$ & $\begin{array}{l}\text { Derechos de } \\
\text { propiedad. } \\
\text { Diseño y } \\
\text { operación de } \\
\text { know-how. }\end{array}$ & $\begin{array}{l}\text { Diseño de } \\
\text { know-how. } \\
\text { Patentes y } \\
\text { marcas. } \\
\text { Conocimiento } \\
\text { de las } \\
\text { características } \\
\text { de los usuarios. }\end{array}$ & $\begin{array}{l}\text { I+D+i y know- } \\
\text { how. } \\
\text { Patentes y } \\
\text { marcas. } \\
\text { Diseño y } \\
\text { operación de } \\
\text { know-how. }\end{array}$ \\
\hline $\begin{array}{l}\text { Principales } \\
\text { habilidades } \\
\text { estratégicas de } \\
\text { gestión }\end{array}$ & $\begin{array}{l}\text { El uso de } \\
\text { tecnología es } \\
\text { incorporado en } \\
\text { todos los rubros } \\
\text { para el } \\
\text { fortalecimiento } \\
\text { de la ventaja } \\
\text { competitiva. }\end{array}$ & $\begin{array}{l}\text { El uso de } \\
\text { tecnología está } \\
\text { orientado para } \\
\text { buscar y } \\
\text { consolidar otras } \\
\text { fuentes de } \\
\text { ventaja } \\
\text { competitiva. }\end{array}$ & $\begin{array}{l}\text { Integración } \\
\text { incremental de } \\
\text { nueva } \\
\text { tecnología en } \\
\text { sistemas } \\
\text { complejos. } \\
\text { Mejoramiento y } \\
\text { difusión de } \\
\text { mejores } \\
\text { prácticas. }\end{array}$ & $\begin{array}{l}\text { Diseño y } \\
\text { operación de } \\
\text { sistemas } \\
\text { complejos de } \\
\text { información. } \\
\text { Desarrollo de } \\
\text { productos } \\
\text { relacionados. }\end{array}$ & $\begin{array}{l}\text { Monitoreo de las } \\
\text { necesidades de } \\
\text { los usuarios } \\
\text { avanzados. } \\
\text { Incorporación } \\
\text { de última } \\
\text { tecnología a los } \\
\text { productos. }\end{array}$ & $\begin{array}{l}\text { Desarrollo de } \\
\text { productos. } \\
\text { Explotación del } \\
\text { conocimiento } \\
\text { generado por la } \\
\text { ciencia básica. } \\
\text { Reconfiguración } \\
\text { de las } \\
\text { responsabilidades } \\
\text { de cada división. }\end{array}$ \\
\hline
\end{tabular}


Llamazares, Francisco y Berumen, Sergio A. Cooperar para competir: la cooperación entre empresas como estrategia para el fomento de la competitividad.

\begin{tabular}{|l|l|l|l|l|l|}
\hline & & $\begin{array}{l}\text { Explotación de } \\
\text { los procesos } \\
\text { que permiten } \\
\text { ventajas } \\
\text { tecnológicas. }\end{array}$ & & & \\
\hline
\end{tabular}

Fuente: elaboración propia a partir de Bell y Pavitt (1997).

Sin importar el grado de integración local y la complejidad tecnológica de los clusters, los agentes operan en un ambiente nacional, regional o local, por lo que necesitan el apoyo de las industrias. El apoyo de las industrias requiere de un adecuado funcionamiento de los clusters inter-empresas. Por ejemplo, en el caso de la industria electrónica de productos ensamblados, el sistema bancario, las universidades, las empresas dedicadas al transporte y la infraestructura de comunicaciones; todas éstas, si bien generalmente no pertenecen a los clusters, necesariamente están vinculadas a sus actividades. La calidad y la productividad de las industrias proveedoras (tanto las que están establecidas en la región o localidad de influencia o en áreas aledañas a ella, como las que no) son influyentes en la productividad y en la competitividad de las empresas que conforman a los clusters. En el cuadro 5 se muestra una clasificación tecnológica en base a las actividades económicas de las empresas.

\section{CLASIFICACIÓN Y ETAPAS DE DESARROLLO DE LOS CLUSTERS}

En la mayoría de la literatura referente a los clusters se representan los encadenamientos hacia atrás y hacia adelante de las actividades relacionadas con una empresa en particular. Para efectos de la planificación local se considera la cadena como la fotografía de una industria que engloba a todas las empresas del sector. La validez del enfoque de clusters se sustenta en el argumento seminal de Hirschmann (1964), en el sentido de que el capital debe ser invertido en los sectores industriales con los más grandes y mejores encadenamientos, con lo cual, se supone que tendrá lugar el crecimiento y que éste se verá potenciado por el efecto multiplicador de las ligas hacia atrás y hacia adelante. El elemento primordial en los clusters es el sector motor, que es la generación de actividades económicas de una región o localidad. Las empresas motor requieren de materias primas, maquinaria, equipo y servicios diversos. Las ligas hacia atrás unen a los productores con sus proveedores. Añadidamente, Albu (1997) indica que los clusters son concentraciones sectoriales y geográficas de empresas ligadas que tienen posibilidades semejantes comunes de dinamismo e innovación. Crown (2002) y Sabine (2003), entre otros, hacen referencia a las cadenas globales de productos de consumo como a un encadenamiento de actividades de valor agregado que une a empresas en distintos lugares geográficos implicados en el proceso económico global (y local) y que están representados por una red de agentes. Estas cadenas se caracterizan por estar enfocadas a los mercados.

Por otro lado, si bien el concepto de los clusters tiene sus raíces en el ámbito estrictamente empresarial, éste también tiene plena aplicación a otro tipo de relaciones en los que el factor económico es secundario. De este modo, los clusters son un elemento de plena aplicabilidad a las relaciones entre agentes económicos con actividades preponderantemente lucrativas, como las empresas 
Llamazares, Francisco y Berumen, Sergio A. Cooperar para competir: la cooperación entre empresas como estrategia para el fomento de la competitividad.

(encadenamientos productivos), pero también a otros agentes con fines diversos, como el gobierno, las universidades y los centros de investigación, y las ONGs. En función de ello, un sistema de clusters también puede ser entendido como un conjunto de elementos constituidos por la reciprocidad, la confianza mutua y de los vínculos basados en la cooperación entre los agentes, y que colaboran en la persecución de fines comunes. Los clusters destacan por el grado de interdependencia entre los agentes, los cuales se refieren a los canales activos que tienen el propósito de dinamizar el intercambio económico, el conocimiento, el diálogo y la comunicación entre los agentes participantes, y que éstos compartan sus ventajas en el afán de construir oportunidades comunes y el establecimiento de acuerdos.

En el pasado ha habido diversas formas para describir las aglomeraciones geográficas de empresas dentro de un sector industrial o dentro de diversos giros industriales. La primera oleada de estudios sobre la clasificación de los clusters va de mediados de la década de los ochenta a finales de la década de los noventa. Los primeros estudiosos sobre los clusters señalaron cuatro categorías. La primera son los Clusters Industriales descritos por Porter (1990), y se conforman por grupos de industrias relacionadas por proveedores y/o compradores, o por poseer tecnologías comunes entre sí, o por compartir visiones o proyectos comunes. La segunda son los Clusters Locales estudiados por Enright (1992 y 1993), y se componen de Clusters Industriales en los que los miembros son geográficamente próximos entre sí; se trata de aglomeraciones geográficas de empresas que se dedican a actividades industriales muy similares. La tercera son los Distritos Industriales, ampliamente estudiados por Piore y Sabel (1984), Becattini (1987, 1989 y 2000), Goodman y Bamford (1990), Brusco (1992), Sforzi (1992 y 2003), y por Pyke, Becattini y Sengenberg (1992), entre otros; se trata de concentraciones de empresas relacionadas a través de procesos de producción interdependientes, y usualmente se dedican al mismo giro o segmento industrial y están enclavadas en comunidades delimitadas, pues su contacto es estrecho y permanente. La cuarta es la Red de Negocios y consiste en una comunicación e interacción estrecha entre empresas que mantienen un alto grado de interdependencia; a diferencia de las anteriores, pueden dedicarse a diversos segmentos industriales y estar geográficamente localizadas en distintos sitios.

Una segunda generación de estudiosos sobre los clusters ha tenido lugar a lo largo de la presente década. Autores como Bresnahan et.al (2001), Feldman (2001), Maskell (2001) y Hibbert y Huxham (2010), entre otros, se han especializado en la clasificación detallada de los clusters y de su organización. De acuerdo a sus propuestas, los clusters se clasifican en centrales, complementarios y dependientes. Un cluster innovador es aquel que está fuertemente centrado en industrias Intensivas en Conocimiento, las cuales serán la base de su actividad en términos de valor agregado, inversión neta y empleo. Son clusters que venden nuevas tecnologías a otros distritos industriales, y frecuentemente también a otros países. Estos suelen ser núcleos centrales y predominan sobre la competencia; rivalizan con otros núcleos innovadores o complementan a núcleos centrales no innovadores. En el cuadro 6 se muestra nuestra propuesta de clasificación de los clusters.

Cuando los núcleos centrales no son innovadores su actividad está ligada o centrada en industrias del sector intensivo en información. Suelen ser importantes 
Llamazares, Francisco y Berumen, Sergio A. Cooperar para competir: la cooperación entre empresas como estrategia para el fomento de la competitividad.

centros financieros globales o nacionales, con una fuerte concentración de oficinas corporativas, empresas de consultoría y centros de investigación y/o de educación superior. También pueden estar especializados en industrias intensivas en escala, en cuyo caso, pueden ser focos aislados con alcance mundial; si bien lo anterior puede tener escaso efecto sobre su entorno inmediato, es posible que sus productos se distribuyan en todo el mundo.

Cuadro 6. Clasificación de los clusters.

\begin{tabular}{|l|l|l|l|l|l|l|}
\hline & $\begin{array}{l}\text { Intensivo en } \\
\text { recursos } \\
\text { humanos }\end{array}$ & $\begin{array}{l}\text { Dominado } \\
\text { por el } \\
\text { proveedor }\end{array}$ & $\begin{array}{l}\text { Intensivo en } \\
\text { información }\end{array}$ & $\begin{array}{l}\text { Intensivo en } \\
\text { escala }\end{array}$ & $\begin{array}{l}\text { Proveedores } \\
\text { especializados }\end{array}$ & $\begin{array}{l}\text { Intensivo en } \\
\text { conocimiento }\end{array}$ \\
\hline $\begin{array}{l}\text { Fuente de } \\
\text { tecnología }\end{array}$ & Compra & Compra & Compra & $\begin{array}{l}\text { Desarrollo y } \\
\text { compra }\end{array}$ & Desarrollo & $\begin{array}{l}\text { Desarrollo y } \\
\text { compra }\end{array}$ \\
\hline $\begin{array}{l}\text { Uso de } \\
\text { tecnología }\end{array}$ & Propia & Propia & Propia & Propia & Venta & Venta \\
\hline $\begin{array}{l}\text { Formas de } \\
\text { rivalidad } \\
\text { comercial } \\
\text { dominante }\end{array}$ & $\begin{array}{l}\text { Coste y } \\
\text { precio }\end{array}$ & $\begin{array}{l}\text { Coste, precio, } \\
\text { moda, marca } \\
\text { e imagen }\end{array}$ & $\begin{array}{l}\text { Servicio al } \\
\text { cliente, } \\
\text { imagen, coste } \\
\text { y precio }\end{array}$ & $\begin{array}{l}\text { Diseño, } \\
\text { diferenciación, } \\
\text { coste y precio }\end{array}$ & $\begin{array}{l}\text { Diseño, } \\
\text { servicio al } \\
\text { cliente, } \\
\text { exclusividad e } \\
\text { innovación }\end{array}$ & $\begin{array}{l}\text { Innovación y } \\
\text { servicio al } \\
\text { cliente }\end{array}$ \\
\hline $\begin{array}{l}\text { Tipo de } \\
\text { organización } \\
\text { industrial }\end{array}$ & $\begin{array}{l}\text { Competencia } \\
\text { monopolística } \\
\text { yoligopolio }\end{array}$ & $\begin{array}{l}\text { Competencia } \\
\text { monopolística } \\
\text { yoligopolio }\end{array}$ & Oligopolio & Oligopolio & $\begin{array}{l}\text { Competencia } \\
\text { monopolística }\end{array}$ & $\begin{array}{l}\text { Oligopolio y } \\
\text { competencia } \\
\text { monopolística }\end{array}$ \\
\hline $\begin{array}{l}\text { Ejemplos de } \\
\text { industrias } \\
\text { del sector }\end{array}$ & $\begin{array}{l}\text { Agricultura } \\
\text { pesca, } \\
\text { silvicultura y } \\
\text { minería }\end{array}$ & $\begin{array}{l}\text { Textil- } \\
\text { confección; } \\
\text { alimentos y } \\
\text { bebidas. }\end{array}$ & $\begin{array}{l}\text { Servicios } \\
\text { financieros; } \\
\text { turismo; } \\
\text { transportación. }\end{array}$ & $\begin{array}{l}\text { Automotriz; } \\
\text { siderúrgica; } \\
\text { electro- } \\
\text { domésticos; } \\
\text { ordenadores. }\end{array}$ & $\begin{array}{l}\text { Maquinas- } \\
\text { herramienta; } \\
\text { maquinaria } \\
\text { para } \\
\text { ingeniería } \\
\text { civil; } \\
\text { empresas de } \\
\text { consultoría; } \\
\text { software } \\
\text { especializado. }\end{array}$ & $\begin{array}{l}\text { Químico- } \\
\text { farmacéutica; } \\
\text { aeronáutica; } \\
\text { ingeniería } \\
\text { genética. }\end{array}$ \\
\hline
\end{tabular}

Fuente: elaboración propia.

Un núcleo complementario es aquel cuya actividad está fuertemente ligada a la de un núcleo innovador o un núcleo central, pero que tiene una presencia de industrias o empresas del sector de proveedores especializados que le permite tener capacidades de adaptación de los productos, procesos, rutinas e ideas desarrolladas en núcleos innovadores o centrales a sus condiciones locales, y comercializar dichas adaptaciones hacia otros distritos $u$ otros clusters. Los clusters complementarios suelen especializarse o tener una actividad económica dominada (en términos de valor agregado y/o empleo) por industrias de los sectores intensivos en escala 0 dominado por el proveedor, pero con una presencia mayor al 5\% de actividades del tipo proveedores especializados. Es frecuente que las industrias del tipo intensivas en escala no estén representadas en ellos.

Los clusters dependientes obedecen a las necesidades de materias primas o de reducción de costes de mano de obra no capacitada de los clusters centrales. Su actividad se concentra en industrias intensivas en recursos minerales o en las fases más intensivas en mano de obra de industrias dominadas por el proveedor e intensivas en escala. $\mathrm{Y}$ los sectores intensivos en conocimiento y de proveedores especializados o no están representados o se limitan a operaciones de ensamblaje de los elementos más sencillos. Estos clusters dependientes coinciden con el 
Llamazares, Francisco y Berumen, Sergio A. Cooperar para competir: la cooperación entre empresas como estrategia para el fomento de la competitividad.

antiguo concepto de enclave y de foco aislado respecto al resto del país donde se localizan. Un núcleo es un sistema de clusters donde existen uno o varios clusters centrales, clusters complementarios y clusters dependientes, lo que le da un orden jerárquico y una organización particular al sistema de ciudades del núcleo. Así, los clusters también incluyen la zona rural que les sirve de área de abastecimiento de materias primas y son, por tanto, localidades de prosperidad relativa respecto al conjunto del país; usualmente, estas localidades se caracterizan por una mayor integración de su actividad que la observada para el conjunto nacional (ver Armstrong y Taylor, 2000, p. 437).

Una economía territorialmente integrada es aquella en la cual sus clusters, núcleos, distritos industriales o locales tienen una relación de complementariedad y rivalizan con los de otros países. Una economía que no esté territorialmente integrada manifestará fenómenos de rivalidad o dependencia entre sus núcleos. En este sentido, una economía desarrollada o central tendrá clusters innovadores y clusters centrales, que rivalizarán con algunos de otros países y controlarán a otros clusters de menor jerarquía. Una economía en desarrollo (o semiperiférica) tendrá núcleos complementarios a los de otros países; una economía subdesarrollada (periférica) solo tendrá clusters dependientes de los existentes en otros países.

El estudio de las etapas de desarrollo de los clusters se funda en la necesidad de conocer los conceptos desarrollados sobre la detección de oportunidades de negocios, centrados en industrias tecnológicamente maduras y que están ubicadas en distritos industriales igualmente maduros. En función de lo anterior, las fases de desarrollo de un cluster son: i) gestación; ii) crecimiento temprano; iii) crecimiento tardío; iv) madurez temprana; v) madurez tardía; vi) decadencia y extinción; o, vii) recuperación. Cada una de estas fases ofrece oportunidades de inversión muy distintas y de su elección dependerá la evolución futura del cluster.

Knox, Agnew y McCarthy (2003), Cintra (2004) y Beerepoot (2008), entre otros, han estudiado que las etapas de gestación y de crecimiento temprano de un cluster son las menos documentadas de todas. En los escasos casos registrados se ha identificado que la creación del cluster ha obedecido a un choque externo sobre una región o localidad con ciertas posibilidades de generar prosperidad. En esta fase, las empresas existentes son pequeñas, casi de subsistencia, y generalmente prevalece una combinación de desempleo creciente y el ánimo de emprender nuevas posibilidades de crecimiento. Los sectores empresariales con mayores posibilidades de éxito son las empresas de servicios básicos y las de servicios de alimentación. Los catalizadores que permiten el surgimiento de un cluster pueden ser diversos. Algunos de los cuales son:

- En lugar de capital de riesgo hay ahorro familiar, y en ocasiones un capital generado por el despido de la anterior fuente de ingresos (derivado del finiquito laboral).

- La experiencia empresarial y las instituciones que la apoyan no existen o apenas presentan cierta solidez; frecuentemente se tiene que enfrentar a un ambiente hostil, ya sea porque la sociedad todavía no ha desarrollado un sentido de riqueza y de propiedad privada de acuerdo a los valores que implica la idea de progreso, o porque previamente existía un ambiente burocrático o académico contrario al espíritu empresarial.

- Universidades con centros de investigación de calidad y en sintonía con el 
Llamazares, Francisco y Berumen, Sergio A. Cooperar para competir: la cooperación entre empresas como estrategia para el fomento de la competitividad.

desarrollo de procesos de innovación: toda una rareza en los países periféricos y semiperiféricos. Con frecuencia las cualidades (habilidades, actitudes y valores) suelen diferir entre los tipos de personas.

- Capital social de apoyo. Primero hay que considerar la actitud que manifiestan las personas y las instituciones locales hacia la propiedad privada y la actividad empresarial y, posteriormente, el nivel de capacitación existente entre la población. Al inicio no siempre se cuenta con estos elementos en cantidad y calidad suficiente.

El embrión que permite el surgimiento de un cluster se funda en: i) la necesidad apremiante ante un cambio no esperado y poco entendido; ii) la visión de mayor horizonte de unos cuantos que ven una oportunidad donde el resto sólo percibe dificultades; iii) la disponibilidad de un ahorro familiar que permita iniciar un negocio; y, iv) la disponibilidad de una población con posibilidades de aprender rápidamente, entre otros aspectos. Si la semilla del cluster comienza a tener éxito, los elementos de soporte comienzan a aparecer al percibir oportunidades de ganancia. Personas de mayor capacidad o mayor disposición a aprender emigran desde otras áreas y los menores costes atraen a empresas de bienes raíces, desarrolladores urbanos y empresas establecidas que buscan donde instalar maquilas $\mathrm{y}$, preferentemente, empresas experimentales o interesadas en apoyar a sus empleados en la creación de nuevas empresas (tanto Start-ups como Spin-offs). El capital de riesgo, los parques tecnológicos y las incubadoras o viveros de empresas suelen ser dos de los últimos elementos en aparecer. Cabe enfatizar que no es conveniente la intervención temprana de los gobiernos; las concepciones grandilocuentes sobre polos de desarrollo generalmente terminan en focos aislados y su impacto es relativo, cuando no, pobre o inútil.

\section{CONCLUSIÓN}

La conformación de clusters es una expresión de la cooperación interorganizacional y representa gráficamente el flujo de productos y servicios en un sector industrial. Éstos se integran tanto por los proveedores de materia prima como por los encargados de la distribución final de productos y los servicios post-venta. La conformación de clusters permite a los agentes participantes una serie de ventajas que de forma aislada difícilmente se podrían alcanzar; estas ventajas son un aliciente adicional que tienen los agentes para cooperar, aunque en particular se destaca la optimización de la competitividad. Mediante la conformación de organizaciones cooperativas y clusters a los agentes les es posible lograr una mayor flexibilidad y la eventualidad para obtener nuevos conocimientos respecto a las actividades que conforman la cadena de valor. 
Llamazares, Francisco y Berumen, Sergio A. Cooperar para competir: la cooperación entre empresas como estrategia para el fomento de la competitividad.

\section{REFERENCIAS}

Albu, M. (1997), "Technological Learning and Innovation in the South", SPRU Electronic Working Paper 5, www.sussex.ac.uk/spru

Armstrong, H. y Taylor, J. (2000), Regional Economics and Policy, Basil Blackwell, London.

Ayele, G., Moorman, L., Wamisho, K. y Zhang, X. (2010), "Infrastructure and cluster development", IFPRI Discussion Papers 980, International Food Policy Research Institute (IFPRI).

Becattini, G. (2000), Dal distretto industriale allo sviluppo locale, Bollati Boringhieri, Torino.

Becattini, G. (editor) (1987), Mercato e forze locali: il distretto industriale, II Mulino, Bologna.

Becattini, G. (editor) (1989), Modelli locali di sviluppo, II Mulino, Bologna.

Becattini, G.; Bellandi, M.; Dei Ottati, G. y Sforzi, F. (editores) (2001), I/ caleidoscopio dello sviluppo locale, Rosenberg \& Sellier, Torino.

Beerepoot, N. (2008), "The Benefits of Learning in Clusters: Analyzing Upward Mobility for Skilled Workers in the Cebu furniture Cluster", Environment and Planning A, Pion Ltd, 40(10), pp. 2435-2452, October.

Bell, M. y Pavitt, K (1997), "Technological Accumulation and Industrial Growth: Contrast between Developed and Developing Countries", en D. Archibugi y J. Michie, Technology and Globalisation in Economic Performance, Cambridge University Press, UK.

Bremen, S. et.al. (2005), Clusters and Industrial Districts. An Interdisciplinary Review, Sandusky's Colossus, Little Rock.

Bresnahan, T.; Gambardella, A. y Saxenian, A. (2001), "Old Economy" inputs for the "New Economy" outcomes: cluster formation in the New Silicon Valleys", Industrial and Corporate Change, 10(4), pp. 835-860.

Brett Anitra, G.; McDougall, P. P. y Audretsch, D.B. (2008), "Clusters, Knowledge Spillovers and the New Venture Performance: An Empirical Examination", Journal of Business Venturing, Elsevier, 23(4), pp. 405-422, July.

Brusco, S. (1992), "The Idea of the Industrial District: Its Genesis", en F. Pyke, et al. Industrial districts and inter-firm co-operation in Italy, International Institute for Labour Studies, Geneva, pp. 10-19.

Burrell, G. y Morgan, G. (1979), Sociological Paradigms and Organizational Analysis, Heinemann, London.

Cintra, L. (2003), Growing Clusters and its Measurement, The Cascade Books, Melbourne.

Collison, S.C. (2001), "Developing and Deploying Knowledge for Innovation: British and Japanese Corporations Compared", International Journal of Innovation Management, 5(1), pp. 73-103.

Cooke, P. (2001), "Regional Innovation Systems, Clusters and the Knowledge Economy", Industrial and Corporate Change, 10(4), pp. 945-975.

Crown, V. (2002), Clusters, Regency Press, Manitoba.

De Propris, L. y Driffield, N. (2006), "The Importance of Clusters for Spillovers from Foreign Direct Investment and Technology Sourcing", Cambridge Journal of Economics, Oxford University Press, 30(2), pp. 277-291, March.

Dessy, I. (2007), "Strengthening Cluster Building in Developing Country Alongside the Triple helix: Challenge for Indonesian Clusters - A Case Study of the Java 
Llamazares, Francisco y Berumen, Sergio A. Cooperar para competir: la cooperación entre empresas como estrategia para el fomento de la competitividad.

Region", MPRA Paper 5851, University Library of Munich, Germany, revised 18 Sep 2007.

Enright, M. J. (1992), "Why Local Clusters are the way to Win the Game", World Link, 5, July/August, pp. 24-25.

Enright, M. J. (1993), "The Geographic Scope of Competitive Advantage", en E. Dirven; J. Groenewegen y S. Hoof van (editores), "Stuck in the Region?: Changing Scales of Regional Identity", Netherlands Geographical Studies, 155, Utrecht, pp. 87-102.

Falck, O.; Heblich, S. y Kipar, S. (2008), "The Extension of Clusters: Differences-inDifference Evidence from the Bavarian State Wide Cluster Policy", Jena Economic Research Papers in Economics, Friedrich-Schiller-University Jena, Max-Planck-Institute of Economics, Thueringer Universitaets- und Landesbibliothek.

Feldman, M. (2001), "The Entrepreneurial Event Revisited: Firm Formation in a Regional Context”, Industrial and Corporate Change, 10(4), pp. 861-891.

Foster, J. (2004), "From Simplistic to Complex Systems in Economics", Discussion Papers Series 335, School of Economics, University of Queensland, Australia.

Freeman, C. y Soete, L. (1997), The Economics of Industrial Innovation, The MIT Press, Boston Mass.

Garud, R. y Kumaraswamy, A. (1993), "Changing Competitive Dynamics in Network Industries: an Exploration of Sun Microsystems' Open Systems Strategy", Strategic Management Journal, Vol.14, pp. 351-369.

Goodman, E. y Bamford, J. (editores) (1990), Small Firms and Industrial Districts in Italy, Routledge, London.

Hansen, N.M (1963), Development Pole Theory in a Regional Context, Kyklos, Vol.XX, Fasc.3.

Hibbert, P. y Huxham, C. (2010), "The Past in Play: Tradition in the Structures of Collaboration", Organization Studies, 31(5), pp. 525-554.

Hirschmann, A. (1964), La estrategia del desarrollo económico, Fondo de Cultura Económica, México.

Ionita, F., Ursacescu, M. y Burlacu, S. (2009), "Public Services as Poles of Regional Competitiveness in Sustainable Development", Review of International Comparative Management, Faculty of Management, Academy of Economic Studies, Bucharest, Romania, 10(3), pp. 552-565.

Isaksen (1998), Rationalisation and Regional Clusters as Development Strategies in a Global Economy, Step Group, Oslo.

Karlsson, C. (2007), "Clusters, Functional Regions and Cluster Policies", Working Paper Series in Economics and Institutions of Innovation 84, Royal Institute of Technology, CESIS - Centre of Excellence for Science and Innovation Studies.

Knox, P.; Agnew, J. y McCarthy, L. (2003), The Geography of the World Economy, Hodder Arnold, London.

Kondratiev, N. D. (1926), "The Long Waves in Economic Life", Archiv fur Sozialwissenschaft und Sozialpolitik. Versión digital en inglés: http://cepa.newschool.edu/het/index.htm

Kondratiev. N. D. (1928), The Long Wave Cycle, Versión digital en inglés: http://cepa.newschool.edu/het/index.htm

Lazonick, W. y West, J. (1988), "Organizational Integration and Competitive Advantage: explaining strategy and performance in American Industry", en G. Dosi; D. Teece y J. Chytry, Technology, Organization and Competitiveness, Oxford University Press, UK. 
Llamazares, Francisco y Berumen, Sergio A. Cooperar para competir: la cooperación entre empresas como estrategia para el fomento de la competitividad.

Marshall, A. (1919), Industry and Trade: a Study of Industrial Technique and Business Organization and their Influences on the Conditions of Various Classes and Nations, MacMillan, London.

Maskell, P. (2001), "Towards a Knowledge-Based Theory of the Geographical Cluster", Industrial and Corporate Change, 10(4), pp. 921-943.

Nadvi, K. y Halder, G. (2005), "Local clusters in global value chains", Entrepreneurship and Regional Development, 17(5), pp. 339-363.

Nelson, R. y Winter, S. (1982), An Evolutionary Theory of Economic Change, Harvard University Press, Boston.

Pentland, B. T., Haerem, T. y Hillison, D. (2010), "Comparing Organizational Routines as Recurrent Patterns of Action", Organization Studies, 31(7), pp. 917940.

Piore, M. y Sabel, C. (1984), The Second Industrial Divide, Basic Books, New York.

Porter, M. E. (1990), The Competitive Advantage of Nations, The Free Press, New York.

Prigogine, I. (1997), Las leyes del caos, Crítica, Barcelona.

Pyke, F.; Becattini, G. y Sengenberger, W. (editores) (1992), Industrial Districts and Inter-firm Co-operation in Italy, International Institute for Labour Studies, Geneva.

Sabine, Z. (2003), Clusters and other Organizational Industrial Models, Karakorum Press Club, Johanesburg.

Sforzi, F. (1992), "The Quantitative Importance of Marshallian Industrial Districts in the Italian Economy", en F. Pyke et al., Industrial Districts and Inter-firm Cooperation in Italy, International Institute for Labour Studies, Geneva, pp. 75-107.

Sforzi, F. (2003), The Institutions of Local Development, Ashgate, U.K.

Shoengen, P. (2001), Clusters: a Taxonomical Classification, Dormund \& Stanley Editors, Dublin.

Teece, D.J. (1998), "Research Directions for Knowledge Management", California Management Review, 40(3), pp. 289-294.

Verspagen, B. (2002), Evolutionary Macroeconomics: A synthesis between neoSchumpeterian and post-Keynesian lines of thought, Maastricht University, Maastricht.

Winter, S. (1987), "Knowledge and Competence as Strategic Assets", en D.J. Teece (editor), The Competitive Challenge, Harper and Row, New York. 